\title{
O desafio crítico dos estudos para a paz
}

\author{
The peace studies' critical challenge
}

El desafío crítico de los estudios para la paz

José Manuel Pureza

- Doutor em Sociologia

- Catedrático de Relações Internacionais e pesquisador do Centro de Estudos Sociais da Universidade de Coimbra

- Professor da Faculdade de Economia da Universidade de Coimbra

- Destacam-se, entre seus principais trabalhos, os livros Violência e armas de fogo em Portugal (com organização de José Manuel Pureza, Rita Santos e Tatiana Moura-CES/Almedina, 2016, série "Cosmopolis") e Jovens e trajectórias de violências: os casos de Bissau e da Praia (com organização de José Manuel Pureza, Katia Cardoso e Sílvia Roque -CES/Almedina, 2015).

• $\quad$ E-mail:jmp@ces.uc.pt 


\section{Resumo}

Os estudos para a paz constituem um elemento frequentemente referido no bloco de propostas teóricas que, no quadro do que ficou conhecido como o "quarto debate", veio contestar os pressupostos mais profundos do cânone racionalista e positivista em relações internacionais. Neste texto, tentarei mostrar, em primeiro lugar, como essa identidade da escola dos estudos para a paz foi construída a partir da negociação de tensões internas ao seu próprio discurso. Num segundo momento, ensaiarei uma leitura desse suposto desvirtuamento dos estudos para a paz, interrogando as vias de resgate possível do seu sentido crítico e emancipador originário no nosso tempo.

PALAVRAS-CHAVE: ESTUDOS PARA A PAZ • TEORIA DAS RELAÇÕES INTERNACIONAIS・TEORIA CRÍTICA • JOHAN GALTUNG.

\section{Abstract}

Peace Studies constitute an element often mentioned among the theoretical proposals in the framework of what came to be known as the "fourth debate", coming to contest the deepest assumptions of the realist and positivist approaches in international relations. In this text I seek to clarify how that identity of the Peace Studies School was constructed on the basis of negotiations regarding inner tensions in its own discourse. Afterwards, I will argue about a des-virtualization of peace studies, questioning the avenues for possible rescuing of its original critical and emancipatory meaning in current days.

KEYWORDS: PEACE STUDIES •INTERNATIONAL RELATIONS THEORY •CRITICAL THEORY • JOHAN GALTUNG.

\section{Resumen}

Los estudios para la paz se constituyen un elemento frecuentemente referido en el bloque de propuestas teóricas que, en el cuadro de lo que se ha conocido como el "cuarto debate", contestó los presupuestos más profundos del canon racionalista y positivista en relaciones internacionales. En ese contexto, intentaré presentar, en primer lugar, como esa identidad de la escuela de los estudios para la paz fue construida desde la negociación de tensiones internas a su propio discurso. A continuación, presentaré una lectura de esa supuesta distorsión de los estudios para la paz, cuestionando las vías de rescate posible de su sentido crítico y emancipador original en nuestro tiempo. 
0 s estudos para a paz constituem - não obstante a sua heterogeneidade interna - um elemento frequentemente referido no bloco de propostas teóricas que, no quadro do que ficou conhecido como "quarto debate", veio contestar os pressupostos mais fundos do cânone racionalista e positivista em relações internacionais. Neste texto, tentarei mostrar como essa identidade da escola dos estudos para a paz foi construída a partir da negociação de tensões internas ao seu próprio discurso. Na verdade, importa constatar que o que veio a ser esse seu posicionamento pós-positivista arrancou de um inicial propósito de reforçar a qualidade dos métodos de investigação segundo uma ótica... positivista. Foi esse 0 itinerário teórico do trabalho de Johan Galtung, matricial para essa escola de pensamento. Importa assim regressar a esses momentos fundadores e analisar as condições em que se operou a viragem pós-positivista ulterior. É o que farei num primeiro momento. Sucede, todavia, que o potencial crítico desenvolvido no contexto dessa viragem terá sido - e é essa uma leitura com apoio crescente na literatura - cooptado pelo sistema de saber-poder internacional, dando hoje suporte a políticas de normalização política e económica global. Num segundo momento, ensaiarei uma leitura desse suposto desvirtuamento dos estudos para a paz, interrogando as vias de resgate possível do seu sentido crítico e emancipador originário no nosso tempo.

\section{A "CIÊNCIA DA PAZ"}

Nascidos da distância crítica diante da agenda estreita e intelectualmente pobre das relações internacionais - que a moldou como um discurso explicativo (e, portanto, legitimador) das guerras - os estudos para a paz assumiram-se, desde o princípio, como uma orientação normativa. No entanto, o significado e a intensidade dessa opção normativa foram extremamente disputados. Há realmente duas matrizes contrastantes nos estudos para a paz.

A primeira matriz pode ser sintetizada numa expressão emblemática: "ciência da paz" (Lenz, 1955). Essa perspectiva, que se afirmou como ciência normal nos Estados Unidos nas décadas de 1950 e 1960, se assenta sobretudo numa compreensão patologizante dos conflitos internacionais e orienta-se, por isso, para uma combinação entre a polemologia (como conhecimento "empírico" sobre a realidade multidimensional das guerras) e a resolução de conflitos (como conhecimento "técnico" agregador de fórmulas de gestão e solução dessas guerras). 0 quantitativismo e a neutralidade valorativa foram as apostas principais dessa matriz para a credibilização acadêmica e política desse pensamento (Dunn, 2005, p. 81). Na verdade, polemologia e "ciência da paz" são irmãs gémeas - ambas trazem no seu código genético o mesmo propósito de substituir a velha máxima romana, "se queres a paz, prepara-te para a guerra", por um positivismo confiante em conhecer a guerra para alcançar a paz, fundado na compreensão da mesma guerra como phénomène social "ordinnaire"(Bouthoul, 1939). Nas palavras de Celestino del Arenal (1986, p. 24),

tradicionalmente, a indagação sobre a paz, realizada sobretudo no quadro das Relações Internacionais como disciplina cientifica, foi mais uma investigação sobre a guerra, o conflito e sobre a forma de o evitar do que uma investigação sobre a paz enquanto tal, como estado caracterizador das relações sociais.

Tem razão. Toda uma linha de pesquisa desenvolvida desde os anos 1940 se assentou nessa prioridade analítica. Dela foram pioneiros, desde logo, Quincy Wright (1942) - que, no seu seminal A study of war, ensaiou uma classificação das guerras em função das suas causas - e Lewis Richardson - cujo Statistics of deadly quarrells classifica os conflitos entre estados com base no número de vítimas e os estuda na sua duração, frequência e repetição (Dunn, 2005, p. 44). Essa combinação entre a centragem empírica nos conflitos e uma metodologia de análise positivista - que tinha tido em Theodor Lenz um cultor de grande prestígio - tornou-se uma aposta acolhida pela comunidade científica nos Estados Unidos, quer dando voz à responsabilidade social dos cientistas, ${ }^{2}$ quer integrando de forma crescente a reflexão acadêmica. ${ }^{3}$

2 De que o Pugwash Movement, na sequência do manifesto de Bertrand Russell e de Albert Einstein, veio a ser a expressão mais destacada.

3 Vejam-se, designadamente, os trabalhos desenvolvidos no Michigan Center for Research on Conflict Resolution e no Center for Advanced Study in the Behavioural Sciences da Universidade de Stanford. 


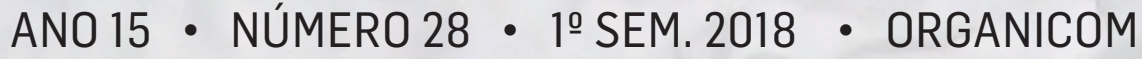

O DESAFIO CRÍTICO DOS ESTUDOS PARA A PAZ

A criação do Journal of Conflict Resolution, em 1955, foi a culminação dessa dinâmica de afirmação de um movimento em que pontuaram nomes como os de Harold Lasswell, Kenneth Boulding ou Anatol Rapoport. Como lembram Reid e Yanarella (1976, p. 316), o Journal of Conflict Resolution foi se movendo paulatinamente de uma agenda inicial em que havia ainda lugar para o debate teórico à condição de technically-oriented, value-obscured and theoretically vacuous organ. Essa progressiva normalização epistemológica e metodológica do Journal foi, para os autores agora referidos, parte de uma dinâmica mais vasta de "capitulação" dos estudos para a paz às mãos das tendências dominantes nas Ciências Sociais de então, em que integraram outros indicadores, como a mudança da designação do centro da Universidade da Pensilvânia de Peace Research Society (International) para Peace Science Society (International) e a "quase eliminação do pluralismo metodológico e do debate político pelas figuras centrais deste campo" (Reid; Yanarella, 1976, p. 316). Em fundo, evidencia-se nessa abordagem o que Herman Schmid veio mais tarde a designar por "reducionismo dos conflitos", ou seja, "uma tendência para definir os conflitos que reduz a sua frequência, a sua importância e a sua severidade, tornando-os geríveis e passíveis de controlo pelo núcleo de decisão do sistema" (Schmid, 1968, p. 224). Em última análise, escrevia ele, "o reducionismo dos conflitos é obviamente causado por uma visão negativa dos conflitos. Para a peace research, o conflito é algo para ser resolvido" (Schmid,1968, p.228). Foi, em grande medida, uma visão da conflitualidade que animou esse arranque dos estudos para a paz, guiado por uma busca de rigor positivista e pela ambição de ser ciência aplicada. Tratava-se, na verdade, de compreender a guerra como "fenómeno tão susceptível de ser investigado como tantos outros" e de "adquirir e codificar conhecimento suficiente para ter a capacidade de explicar a sua presença, ausência ou magnitude". 0 propósito de intervenção terapêutica era evidente: "Se pudermos continuar onde Wright e os seus companheiros fundadores nos deixaram, podemos ainda construir a mais válida das ciências aplicadas que o homem alguma vez conheceu" (Singer, 1970, p. 540).

\section{PELA MÃO DE GALTUNG}

A essa matriz continuísta dos estudos para a paz opõe-se outra, feita quer da recusa do positivismo como código de conhecimento, quer da recusa da solução pragmática de problemas como vocação. Johan Galtung é invariavelmente referido como o nome de referência dessa inversão epistemológica operada na peace research a partir da década de 1970. E, no entanto, uma avaliação atenta da obra de Galtung assinalar-lhe-á uma indiscutível marca de ambiguidade.

Como lembra Peter Lawler (1995, p. 15), "o jovem Galtung foi em grande medida um produto da comunidade da Sociologia americana dos anos cinquenta". Desde logo, pela sua demonstração de fé num positivismo inflexível. Herdeiro em simultâneo de um funcionalismo à la Merton e da relação saint-simoniana de confiança entre reformismo social e ciência, o primeiro Galtung abraçou os estudos para a paz sobretudo na perspectiva de o retirar à especulação filosófica e à razão transcendental e confiar ao "método científico" a identificação dos valores que propiciassem uma avaliação crítica do sistema internacional e da sua funcionalidade (Lawler, 1995, p. 40). Foi esta fidelidade escrupulosa à suposta superioridade do empirismo positivista que afastou Galtung do pensamento tradicional sobre a paz. Para ele, quer a disciplina de relações internacionais, quer a alternativa da "ciência da paz" trabalhada por Lenz, Rapoport ou Richardson enfermavam de insuficiências claras a esse respeito: aquela, porque a hegemonia realista a afastava por definição de qualquer preocupação com a realização da paz; esta, porque não repudiara a vaguidez no conceito de paz que lhe servia de centro. Para o jovem Galtung, a marca de tal pensamento é a indolência - um pensamento apriorístico e dogmático que assume o valor definitivo de algumas máximas abstractas que a História sedimentou. Ora, em contraste com essa forma pré-científica de pensar, de matriz metafísica ou teológica, Galtung afirmou reiteradamente a necessidade de uma abordagem muito mais exigente da construção da paz, que não se cingisse ao conhecimento rigoroso do passado para dele extrair ilações de regulação epistemológica e que propiciasse antes uma exploração de alternativas futuras ao sistema existente, consistente e fundada empiricamente. 0 que ressalta na fase inicial da sua reflexão é, pois, a preocupação em afastar quer o fatalismo realista, quer a limitação da ciência da paz nascente - e em investir seriamente num rigoroso trabalho de fundamentação empírica da avaliação do 
sistema internacional concreto, visando identificar consonâncias e desvios relativos a uma realidade internacional "pura", descontaminada de subjectividades artificialmente segmentadoras. Em síntese, a ambição distintiva dos estudos para a paz no início dos anos 1960 foi combinar voluntarismo ideológico e normativo com empiricismo metodológico (Krippendorf, 1973, p. 184; Neufeld, 1993, p. 167). E, precisamente nessa perspectiva de reforço de uma ciência pura das relações internacionais, as elaborações de Galtung na década de 1960, a começar pelo editorial do número fundador do Journal of Peace Research, definem a integração do sistema internacional como o horizonte de um conhecimento sério e rigoroso da realidade. Para essas elaborações iniciais, o estatocentrismo era, afinal, o resultado de um errado primado do subjectivismo sobre a objectividade que faria obscurecer a natureza e a dimensão sistémicas da realidade internacional, favorecendo o fragmento em detrimento do todo. 0 que verdadeiramente deveria distinguir as relações internacionais da ciência política seria a sua assunção de toda a estrutura de interacção global como objecto de estudo (Galtung, 1975a), afastando assim a escala estatal como dogma.

Foi essa opção que deu sentido ao conceito de paz positiva, avançado logo no editorial de 1964. À paz negativa, entendida como ausência de guerra e de violência física, contrapor-se-ia a paz positiva, entendida como "integração da sociedade humana" (Galtung, 1964, p. 2). Antecipando o que viriam a ser cânones do nosso tempo, Galtung contrapõe a paz negativa, materializada na ambição de peace-keeping, à paz positiva concretizada no trabalho de peace-building e reúne-as num mesmo horizonte de peace-making (Galtung, 1985, p. 145). Esse conceito de paz positiva - muito próximo do de "prevenção de conflitos", ensaiado por John Burton (1990) - é, ele próprio, um precipitado da orientação positivista sufragada por Galtung, pois que assentaria na identificação de duas tendências empíricas globais: o desenvolvimento de uma capacidade para a identificação com os outros e a tendência para a autolimitação no uso da força. Na raiz da noção de paz positiva está, pois, o horizonte da integração da humanidade, que Galtung $(1964$, p. 1) pontua de forma muito clara:

contacto acrescido por meio do intercâmbio [...], compreensão acrescida pelo estudo [...] e o mais que seja até uma cooperação funcional entre grupos ou nações pela cooperação técnica e cultural ou das políticas de comércio e à fusão institucional [...] até atingir o Estado mundial.

O conceito de paz no jovem Galtung era, assim, conotado com o funcionamento de um sistema social global integrado, cabendo ao investigador para a paz o trabalho típico de um médico dedicado à preservação e melhoria da saúde desse corpo global (Lawler, 1995, p. 54). A função primordial do investigador para a paz seria, por isso, não a de fundar filosófica ou eticamente a obrigação de dar prioridade à paz, mas antes a de determinar seu conteúdo com base empírica e explorar os meios para a sua realização (Lawler, 1995, p. 47). Aquela comparação entre a peace research e a medicina, que habita aliás toda a obra de Galtung - e que reforça metaforicamente a pretensão de vincar a objectividade do trabalho científico orientado para a paz - inclui, nos seus escritos iniciais, uma visão dos peace researchers como profissionais recrutados em meios não militantes, de modo a que pudessem se tornar "cientistas sociais comuns ou em técnicos de tipo relativamente desideologizado" (Galtung, 1975b).

Paradoxalmente, a mesma aspiração a uma "boa teoria social", que havia fundamentado esses traços da obra inicial de Galtung, veio a motivar duas rupturas essenciais operadas por sua obra posterior, que fizeram dos estudos para a paz uma das principais expressões da emergência da teoria crítica em relações internacionais. A primeira dessas rupturas ocorreu no plano metodológico e conduziu a peace research de um positivismo reforçado a um assumido pós-positivismo. A segunda ocorreu no domínio substantivo e levou essa corrente da centragem num conceito de paz positiva orientado para a integração à concentração na identificação das práticas de violência estrutural ou latente. Desde logo, o primado do empirismo, defendido por Galtung como contraponto de um subjectivismo abstracto dogmatizado, veio a ser sujeito a uma forte erosão. Esse primado não era mais do que suporte de uma ciência canonizadora da realidade social dominante (Galtung, 1972, p.352) - uma ciência articulada sobre a busca da previsibilidade resultante das permanências descontextualizadas e, como tal, perpetuadora do status quo. "Ao excluir o discurso normativo, a ciência empiricista tinha-se transformado de crítica da razão dogmática em 
sua instância" (Lawler, 1995, p.116). Fiel ao seu propósito de resgatar a ciência na análise do sistema internacional, Galtung incorporou gradualmente a exigência de uma prática científica que não abdicasse de moldar o futuro. Foi, em grande medida, essa noção de que a ciência positivista se perfilava como discurso do presente eterno (Galtung, 1972, p.350) e que mais ciência significaria assumi-la como guia da realização de um futuro preferível (Chadwick, 1996, p.2) que norteou a viragem metodológica da peace research liderada por Galtung a partir da década de 1970. Uma ciência que potencie a busca de outra realidade - e não uma ciência que dê a conhecer a realidade que está - passou a ser seu horizonte de trabalho. No centro desse distanciamento progressivo diante dos cânones positivistas esteve, pois, o estatuto dos dados empíricos. A validação exclusiva das proposições teóricas pelo seu confronto com os dados teve como reverso a exclusão da sua validação por confronto com valores que impusessem um futuro alternativo. Foi nesse contexto que emergiu sua proposta de uma ciência trilateral, que procurou acima de tudo trazer os valores para o mesmo plano de importância epistemológica dos dados e das teorias. À aparência de cedência ao pensamento pré-científico, Galtung respondeu com uma denúncia: a ortodoxia empiricista sempre escondeu uma agenda valorativa, mas revelou-se epistemologicamente incapaz de a reconhecer; tratar-se-ia agora de assumir explicitamente essa condição, dando estatuto epistemológico a uma ciência axiológica a par de uma ciência empiricamente edificada. A nova triangulação do trabalho científico seria pois entre empiricismo - avaliando as teorias pela sua consonância com os dados -, criticismo - avaliando a consonância da realidade empírica com os valores - e construtivismo - avaliando as proposições teóricas pela sua consonância com esses mesmos valores-guia. Em cada um desses registos vai envolvida uma temporalidade diferente: o empiricismo lida sobretudo com os problemas do passado, o criticismo com os problemas do presente e o construtivismo com ensaios de futuro. Mais se sublinha, assim, a centralidade conferida pela investigação para a paz, a partir de então, à criação de novos valores, de novas teorias e de uma nova realidade, tendendo para uma coincidência entre o observado, o previsto e o preferível (Galtung, 1972, p. 361; 1985, p.153).

Esta ruptura metodológica exprimiu, portanto, um profundo e disseminado descontentamento com a teoria social dominante, que se havia tornado uma ortodoxia tecnocrática de legitimação do status quo.

Foi no bojo da procura de um discurso alternativo, assumidamente value-committed e não aparentemente value-neutral, que se inscreveu a ruptura substantiva operada nos estudos para a paz a partir da década de 1970. No centro dessa ruptura está o conceito de violência estrutural. Galtung sintetizou-o como limitação das potencialidades de realização humana provocada por relações de poder, de desigualdade ou de opressão (Galtung, 1969, p. 171) e, com isso, ampliou e radicalizou muito significativamente a agenda da peace research (Terriff, 1999, p. 72). Houve algo de táctico nessa abertura conceptual. 0 próprio Galtung (1975b, p. 2) havia reconhecido que os estudos para a paz estruturados em torno da paz negativa "tornarse-ão [...] facilmente em investigação sobre as condições de manutenção do poder, de cristalização do status quo, sobre a manipulação do dominado para que este não pegue em armas contra o dominador". Ora, como vimos, a isso o mesmo Galtung havia contraposto um conceito de paz positiva materializado num ideal de integração do sistema internacional. A vaguidez política dessa alternativa alimentou críticas implacáveis. Assim, Herman Schmid (1968, p. 221) pôde escrever que "a peace research adoptou uma perspectiva do sistema e uma orientação valorativa idênticas às das instituições internacionais existentes e muito próximas das dos países ricos e poderosos". Para ele, a noção galtunguiana de paz positiva não era mais do que um guarda-chuva que abrigava consensos politicamente equívocos. Acima de tudo, o entendimento dos investigadores para a paz como especialistas neutros identificados com os "interesses do mundo" indiferenciados (a integração como horizonte), numa posição de simetria relativamente às partes num conflito, deveria ser percebido como expressão de uma ortodoxia tecnocrática politicamente orientada sem o assumir explicitamente (Schmid, 1968, p. 229). Por isso, Schmid reclamava dos investigadores para a paz um desempenho totalmente distinto, centrado sobre a revelação das violências latentes e, para isso, disponível a encorajar a polarização social (Schmid, 1968, p. 227). Também Lars Dencik (1970, p. 79) advertia contra a transformação dos estudos para a paz numa tecnologia de controlo e de pacificação animada por uma idealizada harmonia de interesses últimos entre os conflituantes, que mais não era do que uma "fixação ideológica liberal", à qual importava contrapor uma perspectiva objectiva que desse visibilidade ao que ele apelidava de "violência estrutural 
silenciosa" (Dencik,1970, p.82). Stohl e Chamberlain (1972, p. 525) viam a investigação para a paz então dominante guiada por um piecemeal approach que assumia o conflito como absoluto, desligado das causas estruturais, sendo tarefa dos estudos para a paz aliviar a violência pela pacificação imediata dos antagonistas e não a actuação na reformulação do sistema que havia originado as pretensões conflituantes.

A centralidade que o conceito de violência estrutural passou a ocupar na obra de Johan Galtung - e, por intermédio dela, na agenda dos estudos para a paz - foi uma resposta à pujança dessas críticas. Definindo a violência de modo extremamente amplo - como distância artificialmente provocada entre as realizações e as potencialidades humanas - Galtung (1969, p. 168) fez assentar a violência estrutural na distinção básica entre violência pessoal e directa, de um lado, e violência estrutural e indirecta, do outro, e identifica esta com a injustiça social, ou seja, com a distribuição desigual dos recursos e do poder de decidir sobre a distribuição dos recursos (Galtung, 1969, p. 171). Noutro passo, identificará as estruturas de violência como "contextos em que indivíduos podem causar imenso dano a outros seres humanos sem nunca terem pretendido fazê-lo, desempenhando somente os seus deveres normais como função definida pela estrutura". Em qualquer dos casos, "[v]iolência é violência [...], independentemente do modo como é exercida: depressa ou devagar, de modo intencional ou não" (Galtung, 1969, p. 146).

Daí em diante, a inicialmente vaga noção de paz positiva ganhou contornos mais nítidos, ao passar a ser sinónimo de ausência de violência estrutural e não só física. Nas palavras do próprio Galtung (1969, p. 183),

a paz concebida dessa forma diz respeito não apenas ao controlo e à redução do uso aberto da violência, mas ao [...] desenvolvimento vertical. Isso significa que a teoria da paz está em íntima conexão não só com a teoria dos conflitos, mas também com a teoria do desenvolvimento. E a investigação para a paz, definida como investigação das condições - passadas, presentes e futuras - da realização da paz, terá também relação muito próxima com a investigação sobre os conflitos e a investigação sobre o desenvolvimento; aquela normalmente mais relevante para a paz negativa e esta mais relevante para a paz positiva.

Em "A structural theory of imperialism", publicado em 1971, Galtung deu um passo decisivo na concretização da equivalência entre paz positiva e fim da violência estrutural, trazendo-a para o plano de análise do sistema internacional. Na verdade, a teoria estrutural do imperialismo é "uma teoria de libertação da violência estrutural", preocupada fundamentalmente em conceber, explicar e afrontar a desigualdade, sobretudo entre o centro do centro e a periferia da periferia, como forma fundamental de violência estrutural (Galtung, 1971, p. 81). 0 que mais sobressai nesse texto é a rejeição simultânea quer da matriz economicista da construção marxista-leninista do imperialismo, quer da matriz politicista perfilhada pela tradição geopolítica realista, quer ainda da falácia liberal da interdependência. 0 imperialismo é antes perspectivado como resultado da actuação simultânea de dois mecanismos: a relação de interacção vertical entre centros e periferias e a estrutura de interacção feudal (Galtung, 1971, p. 85) - e a sua condição de expressão da violência estrutural à escala mundial é clara: "Só um imperialismo imperfeito e amador necessita de armas; o imperialismo profissional baseia-se na violência estrutural e não na violência directa" (Galtung, 1971, p. 91). Assim, um horizonte alternativo se assenta em duas dinâmicas complementares: maior horizontalização da relação entre centro e periferia e desfeudalização da estrutura geral de relacionamento internacional. A paz positiva, enquanto eliminação da violência estrutural, envolve essas duas exigências. Os estudos para a paz são portanto, por definição, activamente anti-imperialistas. 0 cisma na grande igreja dos estudos para a paz estava definitivamente instalado e pôs, pois, frente a frente, a "ciência" e a "ideologia", nos termos do nome de referência da escola americana, Kenneth Boulding (1978, p. 345), ou "a investigação para a pacificação" e "uma investigação de tipo emancipatório" - ou ainda "a investigação liberal para a paz" e a "investigação crítica para a paz" (Wiberg, 2005, p.24). Considerando a ciência normativa como "uma ocupação perigosa", Boulding (1977, passim) qualifica a paz positiva e a violência estrutural como "metáforas mais do que modelos", cuja transformação em categoria analítica é, em seu entender, profundamente errada. Na sequência desse juízo negativo, procede a uma arrumação das diferentes correntes da peace research em três grandes grupos: os evolucionistas 
(em que inclui a si próprio), os estruturalistas (em que inclui Galtung) e os dialécticos (como Schmid), sendo que estes dois-os "rebeldes europeus" ou "radicais", nas palavras de Terriff (1999, p. 71) - se associam num distanciamento do padrão de trabalho verdadeiramente científico para se envolverem numa construção ideológica que não tem finalidades de produzir conhecimento, mas de intervir politicamente. E se o distanciamento diante do estruturalismo de Galtung se traduziu na acusação de que ele conduziria a uma diluição da especificidade da investigação para a paz na "ambição de estudar virtualmente todos os problemas sociais" (Boulding, 1970, p. 11) - o que levou Lawler (1995, p. 145) a ver nessa dinâmica de inclusão infinita o risco de converter a peace research num "buraco negro intelectual" e Dunn (1978, p.257) a advertir que "os cínicos podem argumentar que a investigação para a paz parece ser um novo refúgio para aquelas boas pessoas que habitualmente apoiam as boas causas (isto é, as causas perdidas). Quanto ao suposto "bloco radical", o anátema de Boulding (1970, p. 9) não podia ser mais claro: "a investigação para a paz radical é um drástico retrocesso para um quadro de referência que ficou desacreditado há pelo menos uma geração". De algum modo, o sentido dessa crítica haveria de ser condensado na ironia de Agrell (1988, p. 96) ao se referir ao "risco para o investigador de se tornar mais um político que um cientista"; ele se interroga se o papel da investigação para a paz deve afinal ser o de ser a Rand Corporation dos bons. Radicalização e ampliação do campo da investigação para a paz foram, pois, as marcas desse tempo. Essa ampliação haveria, aliás, de ser acrescida, já em 1990, pela inclusão da violência cultural no mapa galtunguiano. Essa terceira dimensão das violências refere-se a qualquer aspecto da esfera simbólica da existência - da religião à arte, da linguagem à ideologia - usado para legitimar socialmente a violência directa ou a violência estrutural. A violência cultural, actuando por mecanismos de interiorização, faz com que as violências directa e estrutural pareçam correctas ou que, pelo menos, não pareçam erradas (Galtung, 1990, p. 261). A esta ampliação substantiva corresponde uma diversificação das temporalidades das violências: "a violência directa é um facto, a violência estrutural é um processo e a violência cultural é uma invariância, uma permanência" (Galtung, 1990, p. 264). 0 "triângulo da violência" foi a imagem encontrada por Galtung para representar os relacionamentos entre os três tipos de violência. $E$, embora identifique fluxos de causalidade em todos os lados do triângulo, há uma leitura privilegiada que parte da violência cultural, passando pela estrutural e se materializando na directa (Pureza; Moura, 2005,p.48).

\section{O TRIUNFO POLÍTÍCO DOS ESTUDOS PARA A PAZ?}

A enorme tempestade epistemológica da década de 1970 amainou nos anos seguintes. Do ponto de vista metodológico, a estabilização da ciência normal se processou sem sobressaltos. 0 quantitativismo crescente do Journal of Conflict Resolution, dando expressão às teorias dos jogos ou a sofisticadas modelizações matemáticas, foi acompanhado por uma assinalável escassez de estudos com fundamentos epistemológicos e ontológicos inovadores quer no Journal of Peace Research, quer na literatura em geral. Os termos cáusticos de Galtung a esse propósito são sintomáticos: "Esqueçamos o Journal of Peace Research. Ele traiu toda a ideia da investigação para a paz. Para mim, o Journal of Peace Research é só mais uma revista americana de relações internacionais." (Galtung apud. Jutila; Pehkonen; Väyrynen, 2008, p. 628) A institucionalização da peace research exigiu a canonização de uma agenda de investigação e de um discurso que fossem "politicamente seguros e que não colocassem ameaças potenciais ao sistema existente" (Stohl; Chamberlain, 1972, p. 526).

No plano substantivo, os constrangimentos da Guerra Fria - em especial a intensidade inédita do potencial de destruição atingido pelas duas superpotências, expressa nas doutrinas da second-strike capability - foram determinantes para essa normalização. A agenda dos estudos para a paz acompanhou a consequente recentragem da agenda internacional e do movimento pacifista internacional sobre a corrida armamentista e o desarmamento. A temática privilegiada na produção teórica foi sintomática dessa recentragem: equilíbrio do terror e dissuasão (Tunander, 1989, p. 353-365; Weede, 1983), modelos de análise das dinâmicas de armamento e desarmamento (Intriligator; Brito, 1984; Smith, 1980) e efectividade das sanções econômicas (Lawson, 1983; Tsebelis, 1990) passaram a ser os tópicos principais. Eles exprimem uma reaproximação dos peace studies à agenda dos países do centro do sistema-mundo - e essa reconquista de hegemonia pelo centro tem outro lado: 
a instalação progressiva de uma tendência de os estudos para a paz abordarem a realidade dos países periféricos, como 0 mundo dos golpes de Estado, do caos e do desvio à normalidade (Hettne, 1980; Krippendorf, 1974; Stauffer, 1974; Wolpin, 1978).

Ora, a resposta dos estudos para a paz ao fim da Guerra Fria e a acusação de redundância ou de dispensabilidade de que foram alvo diante do novo contexto (Terriff, 1999, p. 78) veio a ser precisamente uma nova reorientação, simétrica à anterior, assumindo de novo a periferia como foco principal de atenção.

0 dado principal desta nova fase da peace researché a recepção do seu discurso transformador anterior (violência estrutural, paz positiva etc.) nas actuais políticas oficiais de dominação do centro sobre a periferia. Essa reconversão da agenda dos estudos para a paz pode ser analisada como um processo em dois tempos. 0 primeiro é o da constituição de uma narrativa radicalizada sobre a condição periférica. A importância conceptual e política conferida às "novas guerras" teorizadas, entre outros, por Mary Kaldor (1999) e ao mundo perigoso dos "estados falhados" anunciado por Zartman (1995) alimenta uma representação da periferia como lugar de ameaça e de caos, em que a ingovernabilidade (invariavelmente atribuída a causas internas) e 0 alegado anacronismo das motivações das suas guerras (justificadas por razões de natureza pré-moderna: as identidades, as religiões...) transformam, mais do que nunca, as borderlands em lugar de missão civilizadora dos países do centro do sistema (Paris, 2002). A internalização das causas legitima a externalização das terapêuticas e aí mesmo ancora 0 essencial do segundo tempo: a canonização da paz liberal como resposta única para a conversão das periferias turbulentas.

O ideário da paz liberal - radicado na convicção kantiana de que a natureza republicana da constituição civil de cada Estado constituiria uma condição essencial para a paz - ganhou novo alento no quadro das teses do fim da História, passando a assumir-se como uma das grandes narrativas, senão mesmo a grande narrativa, do nosso tempo para a organização social e económica. A sua proclamação como verdade apodíctica legitimou a imbricação, gradualmente mais acentuada ao longo desse tempo de pós-Guerra Fria, entre governação nacional e condicionalidades estabelecidas pelos diferentes poderes reguladores internacionais. A paz liberal é, pois, uma paz construída por formas várias de intervenção internacional condicionadora. É certo que se trata de um projecto compósito, em que convergem dinâmicas de paz muito diversas, desde a paz da vitória militar à paz institucional que garante a governação, passando pela paz constitucional assente na democracia e na liberdade económica e pela paz civil fundada no respeito dos direitos e liberdades individuais (Heathershaw, 2008; Richmond, 2007; 2008).

Recorde-se que foi exactamente nessa lógica de agregação de diferentes pazes que Boutros-Ghali pensou na Agenda para a Paz, de 1992, a principal expressão de refrescamento do mandato das Nações Unidas determinada pelo novo clima internacional do pós-Guerra Fria: o trabalho de peace building, e não apenas de peace enforcing ou de peace keeping, retomando, logo aqui, a construção galtunguiana anteriormente enunciada. Ora, essa resposta a uma periferia feita de estados falhados e de guerras de barbárie não é mais do que

uma experimentação que envolve o transplante de modelos ocidentais de organização social, política e económica para estados dilacerados pela guerra como forma de controlo dos conflitos civis: por outras palavras, é a pacificação pela liberalização política e económica. (Paris, 1997, p. 55)

Nas palavras de Richmond (2007, p. 67), essa paz construída de fora para dentro "é uma forma de hegemonia, importada pela via de intervenções coercivas ou construída por intervenções ou engenharias sociais, políticas e económicas". 0 figurino desse intervencionismo tem mudado, é certo. A hegemonia da paz liberal como projecto de governação global já não pode ser identificada na actualidade com a ortodoxia neoliberal da década de 1980. As pressões emergentes no final do século XX para a inclusão de novas exigências - do comércio justo ao cumprimento dos Objectivos do Milénio ou às estratégias de redução da pobreza - na agenda das políticas de cooperação dos países do centro assinalaram o fim da versão hard do programa da paz liberal. Sucedeu-Lhe um programa revisionista (Pugh, 2005, p. 32) - de que o relatório independente "A more secure world: our 
responsibility" (2004) e o subsequente documento do secretário-geral das Nações Unidas, "In larger freedom" (2005), foram suportes essenciais - que deu continuidade, noutros termos, ao essencial da lógica da paz liberal: a insistência na implantação de formas de regulação padronizadas, tomadas como avesso da bad governance das elites endemicamente corruptas das periferias, a insistência na despolitização da economia e na dogmatização do racionalismo capitalista como fórmula única, a insistência na compreensão do desenvolvimento como convergência a um padrão liberal adoptado pelo centro e, mais que tudo, a insistência na representação das periferias como vítimas de incapacidades patológicas só superáveis por formas de governação terapêutica exogenamente determinadas (Pugh, 2005, p. 33-34) são os seus traços mais marcantes.

Não obstante sua variação no tempo, esse intervencionismo da paz liberal tem assumido um horizonte persistente: a moldagem universal das governações nacionais por parâmetros de democracia liberal e de economia de mercado. Ele é, no entanto, subtil. A despolitização dos seus conteúdos é uma outra das suas marcas. State building, nation building, capacity buildinge institutional building são assumidos como meros dispositivos técnicos (Bickerton; Cunliffe, 2007, p. 99), ou não se tivesse transformado a própria soberania dos chamados estados falhados num conceito divisível e susceptível de titularidades diferenciadas para as suas diferentes componentes (Krasner, 2005) - a soberania formal para o Estado territorial e a soberania real para parcerias público-privadas internacionais (entre estados, agências intergovernamentais e organizações não governamentais). A internacionalização da governação das periferias não se prolonga na reivindicação da sua autoria nem das responsabilidades inerentes pelo centro. "Parcerias", "estratégias country-owned", "incremento do local empowerment" - eis o vocabulário que dá conta de que, sendo muito mais invasivas do que as dos velhos impérios do século XIX, as práticas de governação global conduzidas actualmente pelo centro do sistema repudiam retórica e politicamente a densidade de um verdadeiro império - 0 que leva Chandler a apelidar essa nova forma de governação global de "império em negação":

[o] império está em negação não porque não esteja a regular suficientemente (de facto, há muito mais controlo regulatório associado à ajuda, ao comércio e às relações institucionais do que antes) mas porque o poder político das elites que decidem procura revestirse de formas não políticas, terapêuticas ou puramente técnicas, administrativas e burocráticas. (Chandler, 2006, p. 11)

A paz liberal, como entendimento hegemónico da paz no pós-Guerra Fria, não assume a coerção típica do imperialismo tradicional como seu instrumento privilegiado. A sua força reside antes na insinuação de um campo normativo consensual que alimenta uma biopolítica cujas tecnologias delimitam e ordenam os sujeitos dominados por práticas discursivas e por redes de conhecimento e significado. "Onde o internacionalismo liberal antes aspirava a um ideal de governo mundial, a actual governação global liberal passou a dar primazia à administração das populações por meio da implementação de técnicas biopolíticas de poder" (Dillon; Reid, 2005, p. 46).

Sob essa ótica, a paz liberal pretende ser o inverso do subdesenvolvimento e dos riscos conflituais dele resultantes. Devemos a Mark Duffield (2005, p. 256) uma análise sofisticada do desenvolvimento como tecnologia biopolítica implementada no quadro da instalação de mecanismos de governação nacional liberal e das condicionalidades que a garantem:

0 desenvolvimento é um princípio de formação e uma tecnologia de segurança que invoca constantemente sua razão de existir, isto é, o subdesenvolvimento. [...] [0]s constantes desastres humanitários, a diminuição das oportunidades de vida e as divergências sobre elas, que materializam uma crise permanente, raramente são perspectivados como expressão da finitude da auto-reprodução. Ao contrário, para os funcionários do humanitarismo e do desenvolvimento, isso ocorre porque a vida humana subdesenvolvida não é socialmente empresarializada nem, portanto, autossuficiente o bastante. Por outras palavras, trata-se de uma vida a quem ainda tem que ser ensinado como garantir a sua sustentabilidade.

É nessa natureza infinitamente intervencionista do desenvolvimento que Duffield (2002, p. 1053) faz assentar suas potencialidades únicas para dar resposta àquilo que chama de "guerra civil global", travada não por exércitos, mas entre a vida segura e a vida 
não segura, isto é, entre populações apoiadas por regimes de protecção social e aquelas que se condenam a dependerem apenas de si próprias (Duffield, 2008). É essa resposta que passa cada vez mais por novas formas internacionalizadas de governação que abriram as periferias "a uma fiscalização, intervenção e regulação das metrópoles sem precedentes desde o período colonial, numa tentativa de controlar a instabilidade e a resistência geradas pelas falhas do mercado".

0 programa de paz positiva, tão querido à radicalidade originária dos estudos para a paz, acaba, no nosso tempo, por legitimar os exercícios de engenharia social e política desenhados pela nebulosa da governação global liberal (Cox, 2005), que combinam o esvaziamento das soberanias locais com a adopção padronizada, em escala mundial, de modelos de organização social, económica e política como suposta condição da paz (Pureza; Cravo, 2005, p. 12). Nessa mudança, foi o próprio conceito de paz que mudou, passando de condição vivida num certo território para processo contínuo de transformação induzida por intervenções externas. Como escreve Heathershaw (2008, p. 597), "a move from peace to peacebuilding"... Rendidos a uma perspectiva pragmática de solução de problemas, os estudos para a paz tornaram-se, assim, conhecimento útil para a pacificação de um sistema estruturalmente violento.

\section{RESGATAR A TURBULÊNCIA}

Não partilho a opinião de Matti Jutila, Samu Pehkonen e Tarja Väyrynen (2008) de que a peace research é um cadáver que importa ressuscitar, se a expressão pretender significar um corpo teórico que se tornou irrelevante na orientação das políticas de governação global. Sim, é certo que os estudos para a paz se fazem hoje como ciência normal. Mas isso não equivale a uma abdicação dos intuitos transformadores - quer do ponto de vista epistemológico, quer do ponto de vista da relevância política prática - que animaram a corrente na ruptura dos anos 1970. Pelo que ficou exposto, meu entendimento é de que a ciência normal, nos estudos para a paz, neste início do século XXI, é uma combinação de falta de contaminação pelos grandes movimentos que animam o debate teórico em relações internacionais ou em estudos sobre a segurança e auto-reflexividade tranquilizadora e triunfalista da linha dominante dessa área diante da cooptação do seu universo conceptual pelo projecto de paz liberal, transformado, entretanto, em gramática do poder em escala mundial - "the liberal peace is the foil by which the world is now judged", escreve Oliver Richmond (2008, p. 449).

Como sempre, a ciência normal serve à dominação. Esse diagnóstico foi feito por Galtung e seus seguidores no início dos anos 1960 e motivou, como vimos, importantes rupturas epistemológicas nos estudos sobre a paz então desenvolvidos. Estamos hoje em condições idênticas às então experimentadas. Agora como então, as construções teóricas radicais sobre a paz constituem formas de conhecimento subjugado (Skelly, 2002, p. 58). Resgatar o potencial crítico dos estudos para a paz é, por isso, uma imposição de fidelidade dessa área aos seus propósitos fundadores diante da persistência e sofisticação de mecanismos de poder profundo, que alimentam violências mais ou menos naturalizadas e que importa combater em nome de uma paz do quotidiano e da empatia como horizonte das vidas concretas (Richmond, p. 441). É, pois, duplo o desafio da teoria crítica aos estudos para a paz neste tempo: por um lado, o desenvolvimento de uma ontologia e de uma metodologia emancipadoras; por outro, assumir seriamente a actividade política prática como integrante do trabalho nesse domínio (Patomäki, 2001, p. 734).

Sugiro, em seguida, três dinâmicas de mudança que antecipam esse resgate. A primeira é relativa ao horizonte político com que os estudos para a paz se comprometem. É a dinâmica que nos conduzirá do presente colonial ao futuro recíproco. Esse horizonte político impõe como prioridade aos estudos para a paz o reforço e a radicalização do estudo das violências para lá da violência directa, ou seja, das violências estruturais e das violências culturais. No campo das violências estruturais, essa radicalização emancipatória determina colocar no centro da análise aquela que é hoje porventura a mais complexa e mais dura delas: a precariedade das vidas. Não apenas a que se expressa na vulnerabilização dos regimes jurídicos laborais, 


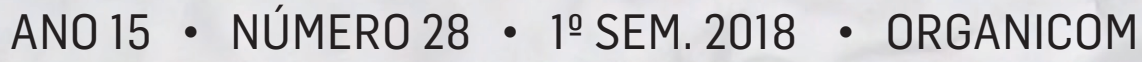

mas também a que se traduz na criminalização das migrações ou a que, em escala mais ampla, se manifesta na perda de densidade da autodeterminação como referência central da autonomia. Essas são violências de colonialidade porque se assentam, todas elas, na negação da autonomia do outro. A paz estrutural que se lhes contrapõe é a que densifica a reciprocidade de prestações e de poder, pressupondo portanto a autonomia de decisão como valor supremo. No plano das violências culturais, o resgate do sentido emancipatório dos estudos para a paz passa por perceber a colonialidade como a expressão do absolutismo filosófico e cultural. Para Joaquin Herrera (2007, p. 58), "[0]s olhares absolutistas [...] apresentamse como se fossem o natural e o racional, entendendo ambos os termos como algo prévio a toda a forma de praxis e de acção social". Por isso, para ele, são três as condições que definem esse olhar: primeiro, a crença em universalismos abstractos; segundo, a crença numa realidade absolutamente objectiva; e terceiro, a crença na existência de um fundamento último de toda a prática social. A descolonização radical dos estudos para a paz e a construção de uma paz cultural arrancam do desarmamento cultural, como lhe chamou Panikkar (1995), o que supõe a crítica do absolutismo colonizador e a densificação alternativa de um modo de pensar que "afirma unicamente a existência de verdades parciais que permitem orientar a busca de coerência entre os nossos desejos, crenças e acções".

A segunda dinâmica de mudança diz respeito à amplitude do objecto dos estudos para a paz. É a dinâmica que nos conduzirá das dicotomias aos continuums. 0 conhecimento dominante tem estado refém de um modo de ver dicotómico. "Guerra e paz" poderia ser a sua síntese. Ora, a própria trajectória do conceito de guerra mostra como sempre foram existindo zonas de indefinição - "nem guerra nem paz" - que, por serem insusceptíveis de encaixar dentro da categorização dicotómica rígida, foram sendo remetidas a uma espécie de gaveta de diversos, com terminologias como "guerras de baixa intensidade", "guerras irregulares" etc. A verdade é que há guerra a mais nas situações de paz formal. 0 resgate do potencial transformador dos estudos para a paz passa, hoje e cada vez mais, pela abertura da sua agenda às "novíssimas guerras" do quotidiano, do espaço doméstico ao espaço urbano e deste aos espaços mais amplos, numa lógica de articulação em continuum ou em espiral impossível de quebrar analiticamente (Cook-Huffman, 2002, p. 42) e, por isso, determinando um colapso de quaisquer escalas exclusivas de análise. Importa que os estudos para a paz reconheçam que se desenvolvem nesses diferentes territórios formas de conflitualidade com actores, condutas e objectivos que são simultaneamente comuns e distintos dos das novas guerras e das guerras vestefalianas (Pureza; Moura, 2005, p. 87). Aliás, se necessário for, aí está o pensamento feminista a evidenciar que a guerra não é um facto social isolado, mas, antes, algo que impregna, como sistema cultural, o nosso quotidiano. A isso mesmo se refere, por exemplo, Betty Reardon (1995, p. 10), ao identificar o patriarcado como "sistema de guerra", isto é, como uma ordem social competitiva, baseada em princípios autoritários, que pressupõe um valor desigual entre seres humanos, que é colocada em prática pela coerção, que institucionaliza a dominação masculina em estruturas verticais e é legitimada pela cultura. É todo esse lastro de guerra trivializado no quotidiano que é preciso escavar e trazer à luz numa ótica renovada aos estudos para a paz. Só assim se incluirão "as vozes e experiências que foram historicamente excluídas ou ocultadas nas teorizações dominantes e universais da violência e da paz" (Cook-Huffman, 2002, p. 43).

Por fim, a terceira dinâmica de mudança é a que arranca do desafio epistemológico e ontológico o que a crítica da ortodoxia racionalista em relações internacionais lança aos estudos para a paz. A consideração de que a paz é uma aspiração dificilmente realizável - por força da natureza humana ou da anarquia endémica do sistema internacional, para os realistas, e da fragilidade das instituições, para os liberais - resulta, para as duas variantes da ortodoxia, na defesa de uma paz única e universal, um discurso sobre e para a paz. Essa unicidade discursiva é o grande alvo de distanciamento teórico quer de quem vê aí défices, quer de quem vê aí excessos. 0 olhar da teoria crítica sobre o discurso da paz da tradição liberal-realista identifica nele graves défices: a sua epistemologia negativa da paz (Rasmussen, 2003) é acima de tudo uma desistência de ambicionar a uma paz que emancipe, começando, desde logo, pela emancipação da própria paz dos constrangimentos de uma representação vestefaliana da realidade internacional, demasiado presa ao imperativo da soberania territorial (Richmond, 2008, p. 452). Todavia, essa pretensão de encontrar uma teoria alternativa pode se tornar, ela própria, fonte de outra imposição hegemónica, ancorada em metanarrativas que mitificam ou naturalizam a agenda dos poderosos de sempre. Não é, pois, de uma teoria alternativa que 
se trata, mas de uma multiplicidade de abordagens que desvelem todas as violências caladas pelos consensos conceptuais. Resgatar o potencial emancipador dos estudos para a paz passa por rejeitar a existência de qualquer ponto arquimediano imposto como suposta objectividade exterior às vidas e em torno do qual se estruturam cartografias da violência, com a sinalização de violências a ter em conta e de violências negligenciáveis. A focagem no quotidiano pessoal e as desconstruções pós-coloniais e feministas abrem campos imensos de agendamento de guerras e de pazes que a vertigem normalizadora roubou, até hoje, à tarefa transformadora que os estudos para a paz vieram enunciar.

\section{REFERÊNCIAS}

AGRELL, Wilhelm. Peace research as the good guys' Rand Corporation? Journal of Peace Research, Thousand Oaks, v. 25, n.1, p. 95-96, 1988.

ALGER, Chadwick. Reflections on peace research traditions. The International Journal of Peace Studies, Taipei, v. 1, n. 1, 1996. ARENAL, Celestino del. La investigación para la paz. In: Cursos de derecho internacional de Vitoria-Gasteiz. 1986.

BICKERTON, Christophe; CUNLIFFE, Philip; GOUREVITCH, Alexander. Politics without sovereignty: a critique of contemporary international relations. Oxon: University College London Press, 2007.

BOULDING, Kenneth. Limits or boundaries of peace research. In: GENERAL CONFERENCE OF THE INTERNATIONAL PEACE RESEARCH ASSOCIATION, 3., 1969, Karlovy Vary. Proceedings... Istanbul: Ipra, 1970a. v. 1.

The philosophy of peace research. In: GENERAL CONFERENCE OF THE INTERNATIONAL PEACE RESEARCH ASSOCIATION,3., 1969, Karlovy Vary. Proceedings... Istanbul: Ipra, 1970b. v. 1.

. Twelve friendly quarrels with Johan Galtung. Journal of Peace Research, Thousand Oaks, v. 14, n. 1, p. 75-86, 1977.

. Future directions in conflict and peace studies. Journal of Conflict Resolution, Thousand Oaks, v. 22, n. 2, p. 342-354, 1978.

BOUTHOUL, Gaston. Sur la fonction presumée et la periodicité des guerres. Revue des Sciences Économiques, p. 161-174, 1939. BURTON, John. Conflict: resolution and prevention. New York: St Martin's Press, 1990.

CHANDLER, David. Empire in dental: the politics of state-building. London: Pluto Press, 2006.

COOK-HUfFMAN, Celia. Paths for peace studies. Peace Review, Abingdon, v. 14, n. 1, p. 41-47, 2002.

COX, Robert. Global perestroika. In: WILKINSON, Rodern. (Org.). The global governance reader. London: Routledge, 2005. p.140-155.

DENCIK, Lars. Peace research: pacification or revolution? Notes on an intra-peace research conflict. In: GENERAL CONFERENCE OF THE INTERNATIONAL PEACE RESEARCH ASSOCIATION, 3., 1969, Karlovy Vary. Proceedings... Istanbul: Ipra, 1970. v. 1.

DILLON, Michael; REID, Julian. Global liberal governance: biopolitics, security and war. Millennium - Journal of International Studies, Thousand Oaks, v. 30, n. 1, p. 41-66, 2001. 
DUFFIELD, Mark. Social reconstruction and the radicalization of development: aid as a relation of global liberal governance. Development and Change, Hoboken, v. 33, n. 5, p. 1049-1071, 2002.

Getting savages to fight barbarians: development, security and the colonial present. Conflict, Security \& Development, Abingdon, v. 5, n. 2, p. 141-159, 2005.

. Global civil war: the non-insured, international containment and post-interventionary society. Journal of Refugee Studies, Oxford, v. 21, n. 2, p. 145-165, 2008.

DUNN, David. Peace research. In: TAYLOR, Trevor. (Org.). Approaches and theory in international relations. London: Longman,1978.

The first fifty years of peace research: a survey and interpretation. Aldershot: Ashgate, 2005.

GALTUNG, Johan. An editorial. Journal of Peace Research, Thousand Oaks, v. 1, n. 1, p. 1-4, 1964.

. Violence, peace and peace research. Journal of Peace Research, Thousand Oaks, v. 6, n. 3, p. 167-191, 1969.

. A structural theory of imperialism. Journal of Peace Research, Thousand Oaks, v. 8, n. 2, p. 81-117, 1971.

. Empiricism, criticism, constructivism: three approaches to scientific activity. Synthese, New York, v. 24, n.3-4, p.343-372, 1972.

. A structural theory of integration. In: . Peace, research, education, action. Copenhagen: Christian Ejlers, 1975a.

Peace research: science or politics in disguise? In: Peace, research, education, action. Copenhagen: Christian Ejlers, $1975 b$.

Twenty-five years of peace research: ten challenges and some responses. Journal of Peace Research, Thousand Oaks, v. 22, n. 2, p. 141-158, 1985.

. Cultural violence. Journal of Peace Research, Thousand Oaks, v. 27, n. 3, p. 291-305, 1990.

HEATHERSHAW, John. Unpacking the liberal peace: the dividing and merging of peace-building discourses. Millennium Journal of International Studies, Thousand Oaks, v. 36, n. 3, p. 597-621, 2008.

HERRERA, Joaquin. O nome do piso: breve tratado sobre arte e dignidade. Florianópolis: Bernúncia, 2007.

HETTNE, Bjorn. Soldiers and politics: the case of Ghana. Journal of Peace Research, Thousand Oaks, v. 17, n. 2, p. 173-193, 1980.

INTRILIGATOR, Michael; BRITO, Dagobert. Can arms races lead to the outbreak of war? Journal of Conflict Resolution, Thousand Oaks, v. 28, n. 1, p. 63-84, 1984.

KALDOR, Mary. New and old wars: organized violence in a global era. Cambridge: Polity Press, 1999.

KRASNER, Stephen. Sharing sovereignty: new institutions for collapsed and failing states. International Security, Boston, v.29, n. 2, p. 85-120, 2005. 
KRIPPENDORF, Ekkehart. Peace research and the industrial revolution. Journal of Peace Research, Thousand Oaks, v. 10 , n.3, p. 185-201, 1973.

Chile, violence, and peace research. Journal of Peace Research, Thousand Oaks, v. 11, n. 2, p. 95-103, 1974.

JUTILA, Matti; PEHKONEN, Samu; VÄYRYNEN, Tarja. Resuscitating a discipline: an agenda for critical peace research. Journal of Peace Research, Thousand Oaks, v. 36, n. 3, p. 623-640, 2008.

LAWLER, Peter. A question of values: Johan Galtung's peace research. Boulder: Lynne Rienner, 1995.

LAWSON, Fred H. Using positive sanctions to end international conflicts: Iran and the Arab Gulf countries. Journal of Peace Research, Thousand Oaks, v. 20, n. 4, p. 311-328, 1983.

LENZ, Theodore. Towards a science of peace. New York: Bookman Associates, 1955.

NEUFELD, Beverly. The marginalization of peace research in international relations. Millennium - Journal of International Studies, Thousand Oaks, v. 22, n. 2, p. 165-184, 1993.

PANIKKAR, Raimon. Cultural disarmament: the way to peace. Louisville: Westminster Fort Knox Press, 1995.

PARIS, Roland. Peacebuilding and the limits of liberal internationalism. International Security, Boston, v. 22, n. 2, p. 54-89, 1997.

International peace-building and the "mission civilisatrice". Review of International Studies, Cambridge, n. 28, p.637-656, 2002.

PATOMÄKI, Heikki. The challenge of critical theories: peace research at the start of the new century. Journal of Peace Research, Thousand Oaks, v. 38, n. 6, p. 723-737, 2001.

PUGH, Michael. The political economy of peacebuilding: a critical theory perspective. International Journal of Peace Studies, Istanbul, v. 10, n. 2, p. 23-42, 2005.

PUREZA, José Manuel; CRAVO, Teresa. Margem crítica e legitimação nos estudos para a paz. Revista Crítica de Ciências Sociais, Coimbra, n. 71, p. 5-19, 2005.

PUREZA, José Manuel; MOURA, Tatiana. Violência(s) e guerra(s): do triângulo ao continuum. Revista Portuguesa de História, Coimbra, n. 37, p. 45-63, 2005.

RASMUSSEN, Mikkel. The West, civil society and the construction of peace. London: Palgrave, 2003.

REARDON, Betty. Sexism and the war system. New York: Teachers College Press, 1995.

REID, Herbert; YANARELLA, Ernest. Toward a critical theory of peace research in the United States: the search for an "intelligible core". Journal of Conflict Research, Thousand Oaks, v. 13, n. 4, p. 315-341, 1976.

RICHMOND, Oliver. The transformation of peace. Houndmills: Palgrave Macmillan, 2007.

Reclaiming peace in international relations. Millennium - Journal of international Studies, Thousand Oaks, v. 36, n.3, p. 439-470, 2008. 
SCHMID, Herman. Peace research and politics. Journal of Peace Research, Thousand Oaks, v. 5, n. 3, p. 217-232, 1968.

SINGER, J. David. From "A study of war" to peace research: some criteria and strategies. Journal of Conflict Resolution, Thousand Oaks, v. 14, n. 4, p. 527-542, 1970.

SKELLY, James. A constructivist approach to peace studies. Peace Review, Abingdon, v. 14, n. 1, p. 57-60, 2002.

SMITH, Theresa. Arms race instability and war. Journal of Conflict Resolution, Thousand Oaks, v. 24, n. 2, p. 253-284, 1980.

STAUFFER, Robert. The political economy of a coup: transnational linkages and Philippine political response. Journal of Peace Research, Thousand Oaks, v. 11, n. 3, p. 161-177, 1974.

STOHL, Michael; CHAMBERLAIN, Mary. Alternative futures for peace research. Journal of Peace Research, Thousand Oaks, v. 16, n. 4, p. 523-530, 1972.

TERRIFF, Terry. Security studies today. Cambridge: Polity Press, 1999.

TSEBELIS, G. Are sanctions effective? A game-theoretic analysis. Journal of Conflict Resolution, Thousand Oaks, v. 34, n. 1, p. 3-28, 1990.

TUNANDER, Ola. The logic of deterrence. Journal of Peace Research, Thousand Oaks, v. 26, n. 4, p. 353-365, 1989.

WEEDE, Erich. Extended deterrence by superpower alliance. Journal of Conflict Resolution, Thousand Oaks, v. 27, n. 2, p. 231-25,4 1983.

WIBERG, Håkan. Investigação para a paz: passado, presente e futuro. Revista Crítica de Ciências Sociais, Coimbra, n. 71, p. 21-42, 2005.

WOLPIN, Miles. Egalitarian reformism in the Third World vs the military: a profile of failure. Journal of Peace Research, Thousand Oaks, v. 15, n. 2, p. 89-107, 1978.

WRIGHT, Quincy. A study of war. Chicago: University of Chicago Press, 1942.

ZARTMAN, William. Collapsed states: the disintegration and restoration of legitimate authority. Boulder: Lynne Rienner, 1995.

Texto recebido em 10.05.2018 e aprovado em 20.06.2018. 